\title{
A IMPORTÂNCIA DA PARCERIA DA FAMÍLIA E A ESCOLA NA EDUCAÇÃO INFANTILE
}

\section{ARTIGO ORIGINAL}

SILVA, Cristiane Rosana da ${ }^{1}$

SILVA, Cristiane Rosana da. A importância da parceria da família e a escola na educação infantil. Revista Científica Multidisciplinar Núcleo do Conhecimento. Ano 04, Ed. 07, Vol. 09, pp. 86-95. Julho de 2019. ISSN: 2448-0959

\section{RESUMO}

O presente artigo tem como objetivo demonstrar a realidade vivida no ambiente escolar e a importância da participação e parceria da família na vida escolar de seus filhos, em especial na fase da educação infantil. É nesse momento que a família descobre que a educação dos filhos deve começar primeiro dentro de seu lar, sendo o dever da escola é capacitar o aluno como cidadão na sua formação escolar, e que somente juntos, escola e a família, alcança-se o objetivo desejado. Feito através de pesquisa, cujo objetivo foi analisar a importância da participação da família no contexto escolar; a relação, da família com a escola, proporcionou a percepção de bons resultados, que nos mostram que pais e professores se aproximam do entendimento do que seja participação, algo significativo na vida das crianças, alunos, família e escola. Nesse contexto, a educação em casa e na escola assumem papéis complementares, que também implicam compartilhar responsabilidades. Pudemos observar que, quando a relação escola e família acontece, ganhamos grandes avanços na aprendizagem e convivência de crianças e jovens, que também passam a valorizar mais a escola e seus aprendizados; falta pouco para essa parceria acontecer de verdade, e tornar a vida de todos muito mais feliz, melhorando a aprendizagem em todos os aspectos.

${ }^{1}$ Graduada em Direito e Pedagogia. 
Palavras-chave: Família, escola, educação infantil.

\section{INTRODUÇÃO}

O presente artigo tem como principal objetivo nos mostrar a importância da parceria família e escola, lembrando que este sempre foi um elo importantíssimo no desenvolvimento da aprendizagem de qualquer criança ou jovem adolescente, ou até mesmo de um adulto. Não há como negar que uma família quando se descuida do desenvolvimento escolar de seus filhos, estes apresentam queda acentuada nos resultados obtidos dos boletins bimestrais, ou seja, na aprendizagem dos alunos, que são refletidos no dia-a-dia em suas vidas, sejam eles, contexto geral, pais, alunos e ou escola.

Levando em consideração que cada um desempenha um papel muito importante e fundamental na sociedade, é preciso, portanto, que a família, seja ela a composição que tenha, cumpra os seus deveres, e que a escola faça valer sua proposta pedagógica como meta, para que ambos possam atingir seus objetivos pretendidos na formação de crianças e jovens adolescentes e adultos. $O$ ideal, e primeiro passo para que isso aconteça, é estabelecer regras que fortalecerão essa parceria, permitindo que a aprendizagem dos filhos e alunos se efetive claramente através de seus desempenhos, tanto no lar quanto na escola.

A família e a escola devem manter sempre um bom diálogo, demonstrar companheirismo e interesse pelos mesmos objetivos, que visam garantir uma melhor aprendizagem ao aluno, seja ela na sua formação pessoal e/ou social, comprometendo alcançar o sucesso na aprendizagem e na formação do indivíduo. Por outro lado, compreende-se que a família precisa ser conhecida e valorizada no contexto escolar, buscando-se sua integração e envolvimento na formação e vida do estudante. 


\section{A IMPORTÂNCIA DA PARCERIA DA FAMÍLIA E A ESCOLA NA EDUCAÇÃO INFANTIL}

Podemos observar que a família é a base, a principal na formação e desenvolvimento da criança. A partir do nascimento, as crianças começam a receber a educação básica para viver em sociedade e exercer a sua cidadania, como: pedir licença, desculpas, agradecer, obedecer, por favor, dividir, compartilhar, respeitar os pais, os avós, os tios (as), os colegas e os mais velhos; aprendem a se comportar adequadamente, a esperar a sua vez, entre outros. A escola dará continuidade no processo educativo vindo da família, e introduzirá a formação acadêmica indispensável para a construção intelectual e profissional do indivíduo - caminhará lado a lado com a família, favorecendo e fortalecendo a formação de valores, através da parceria juntos.

A parceria entre a família e a escola é de suma importância para o sucesso no desenvolvimento intelectual, moral e na formação do indivíduo na faixa etária escolar. [...] Afinal, por que até hoje em pleno século XXI a escola reclama da pouca ou insignificante participação da família na escola, na vida escolar de seus filhos? Seria uma confusão de papéis? Onde estaria escondido o ponto central desse dilema que se arrastam anos e anos? (GARCIA, 2006, p. 12).

Tanto a família quanto a escola desempenham papéis decisivos na educação e formação da criança. Portanto, quando a educação dada no lar, pela família, acontece de forma satisfatória, fazendo o necessário para haver uma integração em parceria com a escola - a partir dessa parceria, a criança se torna um adulto capaz de contribuir positivamente para a construção de uma sociedade mais justa, ampla, mais valorizada. Os pais acreditam que a escola é a continuação do seu lar e na maioria das vezes, cobra dela o que na verdade é de sua função. Nesse período acontece o confronto, pois a partir da entrada do filho na escola, o sistema familiar tem seus valores colocados à prova e exposição.

O mundo está se transformando num lugar cada dia mais perigoso. A tendência natural dos pais é procurar superproteger os filhos, mas esse 
é um erro grave. É possível, no entanto, proporcionar a segurança desejada sem sufocar o desenvolvimento da autonomia das crianças (ARAUJO, 2005, p. 84).

Di Santo (2006), citado por Abatti e Silva (2009) em seu artigo Família e Escola: uma relação de ajuda relata que, atualmente, a família tem passado para a escola a responsabilidade de instruir e educar seus filhos, e espera que os professores transmitam valores morais, princípios éticos e padrões de comportamento, desde boas maneiras até hábitos de higiene pessoal. Justificam alegando que trabalham cada vez mais, não dispondo de tempo para cuidar dos filhos. Além disso, acreditam que educar em sentido amplo é função da escola. E, contraditoriamente, as famílias, sobretudo as desprivilegiadas, não valorizam a escola e o estudo, que antigamente era visto como um meio de ascensão social.

É preciso compreender a família como um fenômeno historicamente situado, sujeito as alterações, de acordo com as mudanças das relações de produção estabelecidas entre os homens [...]. É evidente que as funções da família vão depender do lugar que ela ocupa na organização social e na economia (ARANHA, 1989, p. 75).

O ser humano aprende e ensina o tempo todo, de acordo com as relações sociais submetidas. O papel da família é fundamental e essencial, pois é ela que decide, desde tão cedo, o que seus filhos precisam aprender, o que é necessário saberem para tomarem as melhores decisões em seu futuro.

\section{A FAMÍLIA E A ESCOLA NA EDUCAÇÃO INFANTIL}

Para a escola, a família do aluno é a base indispensável para que aprendizagem aconteça. É preciso muito cuidado ao analisar o comportamento dos alunos em função das famílias de onde provêm para não correr o risco de enquadrá-los em padrões rígidos de valores, crenças e estruturas típicas de modelos que na verdade são construções históricas e produtos culturais que refletem em seus comportamentos. 
Sabe-se que não só no ambiente escolar se dá a aprendizagem, e a criança possui outras referências que não podem ser esquecidas ou menosprezadas neste processo. A escola consiste no espaço em que acontece a interação entre professores e alunos, possibilitando o acesso ao conhecimento formal de dado contexto cultural, sendo um instrumento necessário ao processo educativo.

A família tem o profundo conhecimento sobre o desenvolvimento de seu filho, o qual se torna extremamente valioso para a compreensão de suas necessidades educacionais. Esses conhecimentos incluem informações acerca do desenvolvimento da criança no lar, seus interesses escolares, a família e a criança estabelecem e constroem o conhecimento em um espaço de convivência no qual se aprende e incorpora os valores éticos e os significados afetivos.

A família e a escola precisam buscar sempre um ambiente saudável para a criança, estimulando a sua educação e aprendizagem, pois a qualidade da educação infantil depende cada vez mais da parceria entre família e escola. Ambas precisam trabalhar juntas, contribuindo para preparar um futuro cidadão que respeite o equilíbrio ecológico do planeta, para recriar a paz; para reduzir a violência; preparar em conjunto família/escola, os sujeitos/alunos para viveram num mundo em transformação, e que será bem diferente do atual quando eles concluírem a etapa escolar.

A importância dos aspectos afetivos na relação família/escola pode favorecer a fase inicial de aclimatação da criança, hipótese que também parece se confirmar na literatura. Aponta-se a importância da família na modelagem de valores e expectativas e na promoção da autonomia, baseando-se nos valores, expectativas e fornecimento de suporte à criança.

É primordial que a escola elabore projetos e crie mecanismos para que a família participe ativamente do cotidiano escolar. Somente assim serão parceiros na efetivação do processo ensino e aprendizagem. A vida familiar e a vida escolar devem ser simultâneas e complementares. É preciso que a escola esteja em perfeita sintonia com a família, pois a instituição de ensino deve complementar a formação educacional da criança. Essas duas instituições, família e escola, devem se complementar na 
tentativa de alcançar o objetivo maior que é a formação integral da criança (CORTELAZZO, 2000, P.32).

Não há dúvida de que a influência familiar é decisiva na aprendizagem dos alunos. Os filhos de pais extremamente ausentes vivenciam sentimentos de valorização e carência afetiva, que impossibilita de obter recursos internos para lidar com situações adversas. Isso gera desconfiança, insegurança, improdutividade e desinteresse, sérios obstáculos à aprendizagem escolar (SCOZ, 1996).

Promover a participação efetiva da comunidade escolar através de parceria com os pais e outros segmentos da sociedade, buscando criar condições para promoção de uma educação construtiva e justa através de um trabalho coletivo e educativo dentro da escola. Afinal, é também nela que as crianças aprendem a não reproduzir preconceitos que podem estar arraigados na família. Cabe ao educador promover a aprendizagem da diversidade. Envolver as famílias sem misturar a responsabilidade não é tarefa simples, é importante ter como pilares o diálogo e o respeito mútuo.

Devemos buscar diversas formas para promover a harmonia entre família e escola, uma pauta que deve fazer parte de qualquer trabalho educativo que tem por foco a formação de um indivíduo. E essa harmonia entre escola e família baseia-se na divisão do trabalho de educação de crianças, jovens e adultos, envolvendo expectativas recíprocas, das quais a família ajuda a escola, e a escola por sua vez deve contribuir com a formação do indivíduo para a sociedade em que está inserido.

Os pais convivem com as crianças e muitas vezes não se dão conta de que suas atitudes poderão influenciar positivamente ou negativamente na formação de seu filho, tanto a convivência quanto o relacionamento familiar são fatores fundamentais para o desenvolvimento individual. Entender o indivíduo como parte de um sistema de um todo organizado, com elementos que interagem entre si, influenciando cada parte e sendo por ela influenciado, traz uma luz à compreensão acerca do desenvolvimento humano, contribuindo para a reflexão sobre os contextos familiar e escolar, que podem ser elementos de moderação, inclusão e segurança. 
O papel do professor na sociedade seria o de um profissional que pode colaborar para que os alunos tenham uma visão crítica do mundo, levando-os a ter uma postura autônoma. E para um bom funcionamento desse papel, é conveniente que haja uma ligação direta dessa instância com o educando.

Família e escola sempre formaram um elo importantíssimo no desenvolvimento da aprendizagem de qualquer criança ou jovem adolescente e adultos. A escola, com certeza, não quer que a família seja responsável pelos conteúdos dados, e sim que se ocupe em estimular o filho em suas atividades. Formam uma parceria entre instituições distintas, onde cada um exerce seu papel em prol do mesmo objetivo. Sendo que o papel da família seria o de estimular ao filho o comportamento de estudante e cidadão, e o da escola seria orientar aos pais nos objetivos esperados que o aluno atinja, assim como de criar momentos para que essa integração aconteça de melhor forma possível.

Tendo em vista que a busca de uma boa relação entre família e escola deve fazer parte de qualquer trabalho educativo que tenha como foco a criança, a escola também exerce uma função educativa junto aos pais, discutindo, informando, aconselhando, encaminhando os mais diversos assuntos, para que família e escola em colaboração mútua possam promover uma educação integral da criança - ou seja, a escola ampara os alunos e atende a sua necessidade de formação integral, isso relacionado à competência escolar, e não aos deveres familiares.

A união família/escola gera benefício em relação não só ao processo ensino/aprendizagem, mas também na troca de informações acerca da criança, no desenvolvimento da mesma na escola e em casa. Ou seja, essa inter-relação possibilita compreender atuação da criança tanto em casa como na escola, suas condutas e as relações que estabelece com os adultos no seio familiar (ANDRADE, 2008).

Para tanto, a educação deverá oferecer instrumentos e condições que ajudem o aluno a aprender a aprender, a aprender a pensar, a conviver e a amar. Uma educação que ajuda a formular hipóteses, construir 
caminhos, tomar decisões, tanto no plano individual quanto no plano coletivo (MORAES, 1997, p. 211)

De acordo com Brandão (2010), no art. 2ํ da LDB, a educação é dever da família e do Estado, e é importante que os pais garantam a educação escolar de seus filhos. Esta deve ser inspirada nos princípios de liberdade, proporcionando as condições necessárias para que a criança usufrua de seus direitos e dos seus ideais de solidariedade humana, tendo por finalidade seu preparo e qualificação. É na educação escolar que se obtém o pleno desenvolvimento do educando, devendo considerar que o papel dos pais e das instituições é formar cidadãos capazes de trabalhar e conviver em sociedade.

Afinal, a escola é um lugar que possibilita novas experiências, uma vivência social diferente daquela do grupo familiar, no sentido em que se proporciona um universo de interações pessoais e ambientes diferentes, capazes de provocar transformações no processo de desenvolvimento e na formação do indivíduo para prepara-lo para o convívio social.

\section{CONCLUSÃO}

Este artigo teve como objetivo mostrar à importância da família no processo educativo do aluno/filho, quando se trata do saber "ser e agir", a escola pode contribuir para o fortalecimento da família no ensino-aprendizagem de seus filhos. A instituição escolar e a família são parceiras neste processo, e nenhuma das partes poderá realizar todo o processo de construção de saberes trabalhando isoladamente, podendo resolver coletivamente.

Todas as instituições devem tomar a iniciativa para fortalecer e aproximar pais/alunos/escola por meio de reuniões, palestras que possuam em seu conteúdo informações interessantes tanto para os pais como para os filhos; atividades que apresentem o que os estudantes realizam todos os dias em seus respectivos setores, entrega de boletins para o acompanhamento do progresso do aluno mensalmente trazer profissionais especializados para interagir com a família e outras atividades que 
são importantes para a construção de valores devem ser adotadas por parte da escola.

Todos, família, aluno e escola, precisam unir-se a fim de ensinar, educar, formar e proporcionar conhecimentos, e capacitar o aluno para ser inserido na sociedade.

\section{REFERÊNCIAS BIBLIOGRÁFICAS}

ARANHA, M. L. de. A. Filosofia da Educação. São Paulo: Moderna, 1989.

ARAÚJO, C. A. de. Pais que educam - uma aventura inesquecível. São Paulo: Gente, 2005.

ANDRADE, L. B. P. de. Os centros de convivência infantil da UNESP: contexto e desafios. Dissertação (mestrado em Serviço Social) - Faculdade de História, Direito e Serviço Social da UNESP. Franca, SP. 2003.

BRANDÃO, A. C. P; CARVALHO, M. J. P. As fichas de atividades de linguagem escrita na educação infantil. In: BRANDÃO, A. C P; ROSA, E. C. de S (Org.). Ler e escrever na Educação Infantil: discutindo práticas pedagógicas. Belo Horizonte: Autêntica, 2010.

CORTELAZZO, I. B. de C. Ensinar e Aprender: as duas faces da educação. In: Colaboração, Trabalho em Equipe e as Tecnologias de Comunicação: Relações de proximidade em cursos de pós-graduação: Tese de Doutorado - Faculdade de Educação da Universidade de São Paulo, 2000.

GARCIA, E. G. VEIGA, E.C. Psicopedagogia e a teoria modular da mente. São José dos Campos: Pulso. 2006.

MALDONADO, M. T. P. Comunicação entre pais e filhos: A Linguagem do senti. 20 Ed. São Paulo: Saraiva, 1996. 
MORAES, M. C. Subsídios para Fundamentação do Programa Nacional de Informática na Educação. Secretaria de Educação à Distância, Ministério de Educação e Cultura, Jan/1997.

RODRIGUES, M. I. A importância da parceria família e escola. Colégio Integral. Bahia. Dez/2012. Disponível em: www.integralweb.com.br/a-importancia-da-parceriafamilia-e-escola/. Acesso em: 06 de julho de 2019.

SCOZ, B. J. L. Psicopedagoga e realidade escolar: O problema escolar e de aprendizagem. 3 ed. Petrópolis: Vozes, 1996.

WEBER, G. A; SILVA, I. F. de. S. da. A Importância da família na escola. Faculdade Internacional (FACINTER). Sorriso, MT. 2009. Disponível em: https://monografias.brasilescola.uol.com.br/pedagogia/a-importancia-familia-naescola.htm. Acesso em: 06 de julho de 2019.

ZAGURY, T. Escola sem conflito: parceria com os pais. Rio de Janeiro: Record, 2002.

Enviado: Fevereiro, 2019.

Aprovado: Julho, 2019. 